\title{
Role of plasminogen activator-plasmin system in tumor angiogenesis
}

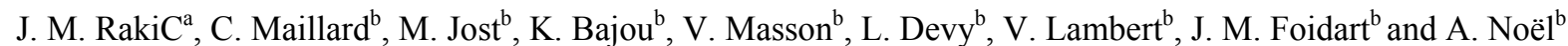 \\ ${ }^{a}$ Department of Ophthalmology, CHU, Sart-Tilman, 4000 Liège (Belgium) \\ ${ }^{b}$ Laboratory of Tumor and Developmental Biology, University of Liège, Tour de Pathologie (B23), Sart-Tilman, 4000 Liège (Belgium)
}

\begin{abstract}
New blood formation or angiogenesis has become a key target in therapeutic strategies aimed at inhibiting tumor growth and other diseases associated with neovascularization. Angiogenesis is associated with important extracellular remodeling involving different proteolytic systems among which the plasminogen system plays an essential role. It belongs to the large serine proteinase family and can act directly or indirectly by activating matrix metalloproteinases or by liberating growth factors and cytokines sequestered within the extracellular matrix. Migration of endothelial cells is associated with significant upregulation of proteolysis and conversely, immunoneutralization or chemical inhibition of the system reduces angiogenesis in vitro. On the other hand genetically altered mice developed normally without overt vascular anomalies indicating the possibility of compensation by other proteases in vivo. Nevertheless, they have in some experimental settings revealed unanticipated roles for previously characterized proteinases or their inhibitors. In this review, the complex mechanisms of action of the serine proteases in pathological angiogenesis are summarized alongside possible therapeutic applications.
\end{abstract}

Key words: Plasminogen; angiogenesis; extracellular matrix; PAI-1; proteinase inhibitor.

\section{Introduction}

Angiogenesis, the formation of new blood vessels from pre-existing ones is essential for sustained tumor growth because it allows oxygenation and nutrient perfusion of the tumor as well as removal of waste products. Moreover, increased angiogenesis coincides with increased tumor cell penetration into the circulation and thus promotes metastasis. Tumor vessels develop by sprouting or intussusception from pre-existing vessels [1]. In addition, circulating endothelial precursors mobilized from the bone marrow can also contribute to tumor angiogenesis [2]. Angiogenesis is controlled by the net balance between molecules that have positive and negative regulatory activity $[1,3,4]$. This observation has led to the concept of the 'angiogenic switch' in which the endothelial activation status is determined by the induction of positive regulators and/or the loss of negative regulators [5]. Positive regulators include at least the vascular endothelial growth factor (VEGF) family, fibroblast growth factors (FGFs), an-giopoietins, cytokines, chemokines, and their tyrosine kinase receptors. An increasing number of negative regulators have been identified such as inhibitors of proteinases, thrombospondins, interferons, chemokines (IP-10 and PF-4), bioactive fragments of the extracellular matrix (ECM) and other molecules [3, 4]. While not the subject of this review, in addition to induction of vascular permeability, proliferation and chemotaxis, VEGFs control endothelial cell survival, an activity necessary to maintain immature vessel integrity during neovascularization [6].

VEGF also increases the expression of matrix metallo-proteinases (MMPs) and protease inhibitors [1]. VEGF expression is upregulated in hypoxia by binding of the hypoxia-inducible factor 1 (HIF-1) to its promoter. HIF-1 itself is regulated via its HIF-1 alpha subunit. Cells lacking a normal von Hippel-Lindau (VHL) tumor suppressor gene show high expression of VEGF due to constitutive stabilization of HIF-1 alpha [7]. At a later stage, angiopoietin 1 stabilizes the endothelial network by stimulating the interactions between endothelial and perien-dothelial cells, and reducing vascular permeability [1]. The formation of a provisional ECM is a hallmark of an-giogenesis. Angiogenic factors, most notably VEGF produced by tumor cells, induce hyperpermeability resulting in the extravasation of plasma proteins including at least fibrinogen, prothrombin, and vitronectin. Tissue factor through the activation of thrombin triggers the formation of fibrin [8]. Together with other adhesive proteins such as vitronectin, laminin, and fibronectin, fibrin forms a provisional matrix which supports angiogenesis and tumor growth [9]. These matrix components control cell proliferation, migration, survival, and apoptosis through interactions with adhesion molecules expressed at the cell surface. Important adhesion molecules include the integrins $\alpha_{\mathrm{v}} \beta_{3}$ and $\alpha_{\mathrm{v}} \beta_{5}$, receptors for fibrin and vitronectin [10-12]. Blockage of $\alpha_{\mathrm{v}} \beta_{3}$ and $\alpha_{\mathrm{v}} \beta_{5}$ integrins withmon-oclonal antibodies or small-molecule inhibitors prevents tumor growth and angiogenesis in animal models [13]. However, tumor-induced angiogenesis occurs and is actually enhanced in $\beta_{3}$-deficient mice and $\beta_{3} / \beta_{5}$ double-knockout mice [14]. These apparently paradoxical data may suggest that rather than being 
required for angiogenesis, $a_{\mathrm{v}} \beta_{3}$ and $a_{\mathrm{v}} \beta_{5}$ integrins might normally function to limit it, and that the real effect of integrin-blocking agents was actually the activation of integrins, a process referred to as the 'integrin-mediated death pathway', leading to inhibition of neovascularization [15]. In an ocular model of hypoxia-induced retinal neovascularization, blockage of integrins in p53 null mice was ineffective in preventing pathological retinal angiogenesis suggesting that $\alpha_{v}$ integrins and p53 act in concert [16]. During angiogenesis, extracellular proteolysis has been implicated in different steps such as provisional matrix remodeling, basement membrane degradation, and cell migration and invasion. Besides degrading ECM components, proteinases have also been implicated in the activation of cytokines, as well as in the release of growth factors sequestered within the ECM [17-19]. The group of proteinases involved in ECM remodeling comprises four different families based on the nature of the chemical group responsible for catalytic activity: the serine, cysteine, aspartic and metalloproteinases [20]. The present review will focus on a serine proteinase family, the plasminogen system which is involved in fibrinolysis, and in the degradation of ECM either directly or indirectly by activating MMPs. Over the last decade, mice deficient in one of the plasminogen system components have been generated allowing to study directly their role in disease [21-27].

\section{The plasminogen system}

The plasminogen system is composed of several protein members: (i) plasminogen, an inactive proenzyme; (ii) urokinase (uPA) and tissue-type (tPA) plasminogen activators, two serine proteinases which convert plasminogen into plasmin; (iii) UPAR, a glycosylphosphatidylinositol (GPI)-linked surface receptor for uPA, and (iv) plasminogen activator inhibitors type 1 and type 2 (PAI-1 and PAI-2) belonging to the serine proteinase inhibitor (ser-pin) family (fig. 1). While sharing in common a plasminogen-converting function, the two types of plasminogen activator (uPA and tPA) have distinct structural and functional features. Briefly, tPA acts mainly as a fibrin-dependent and intravascular activation enzyme which is primarily involved in clot dissolution [28]. In contrast, uPA operates as a fibrin-independent, largely cell surface receptor-bound plasminogen activator and controls pericellular proteolysis [29-31].

The uPA molecule is composed of two major functional domains: the growth factor domain at the $\mathrm{N}$ terminus which binds UPAR and the catalytic domain at the $\mathrm{C}$ terminus. The activities of the uPA system are initiated through a cascade of events originating with UPAR. UPA is secreted as an inactive single-chain proenzyme (scuPA) which binds to uPAR present on many cell types. Cleavage of pro-uPA yields the active enzyme consisting of two disulfide-linked chains. In addition to plasmin, several proteinases including factor XIIa, cathepsin B, and kalikrein have been shown to activate scuPA as well. However, the physiological relevance of some of these proteinases is still questionable [32,33]. Plasmin remains as the most likely physiological activator of scuPA [34]. Each molecule of plasmin can amplify this cascade by activating many more molecules of scuPA, a process which is made very efficient by the localization of both plasminogen and scuPA (by binding to $\mathrm{UPAR}$ ) to the cell surface. Plasmin binding on its receptors is mediated by the lysine-binding site (LBS) associated with the kringle domain of plasmin(ogen). As a consequence of binding, plasminogen activation is enhanced while at the same time being partially protected from inactivation by circulating alpha2-an-tiplasmin [35]. However, ligated plasmin can still be inactivated by aprotinin, which competes with fibrin for the plasmin active site. There is a growing list of ubiquitous plasminogen receptors, including alpha-enolase, cytokeratin 8 , and annexin 11 [36]. Plasmin displays a broad spectrum activity, and is able to degrade many glycoproteins (laminin, fibronectin) and proteoglycans of the ECM, as well as fibrin, and to activate other proteinases such as pro-metalloproteinases (MMP-1, MMP-3 and MMP-9). Plasmin can also activate or release growth factors from the ECM including latent transforming growth factor (TGF- $\beta$ ), basic fibroblast growth factor (bFGF), and VEGF [18].

Thus, uPA present at the cell surface is generally believed to initiate a proteinase cascade which in turn leads to the activation of plasmin, the breakdown of the ECM, and the activation and/or release of cytokines/chemokines or growth factors, thereby promoting cellular migration. However, various observations indicate that the role of the PA system in cell migration is not limited to the induction of matrix destruction. In concert with uPAR and PAI-1, uPA is involved in mitogenic, chemotactic, adhesive, and migratory cellular activities [37-39]. In addition, uPAR is involved in intracellular signaling, and cannot be considered as a simple molecule that localizes uPA at the cell surface $[31,40]$. The binding of uPA to its cell surface receptor concentrates uPA activity to the so-called 'focal adhesion sites' on the cell surface. The uPA/uPAR complex interacts with vitronectin, a multifunctional ECM glycoprotein and with $\beta_{1}$ and $\beta_{3}$ integrins, thereby participating in cell anchoring and migration [41]. In addition, despite the lack of a transmembrane domain, uPAR colocalizes with caveolin which can bind signaling molecules and stimulate signal transduction through uPAR [42-44]. However, the role of UPAR in intracellular signaling will not be discussed in detail in this review. 
Figure 1. The plasminogen/plasmin system in pericellular proteolysis. Plasmin plays a central role by activating matrix metalloproteinases (MMPs) or by degrading extracellular matrix components. uPAR participates both in UPA activation, cell adhesion, and migration, as well as in signal transduction. The inhibitor PAI-1 exerts different effects by controlling the activity of plasminogen activators (tPA and $u P A)$ and by regulating cell adhesion and migration through its interaction with vitronectin (see also fig. 2).

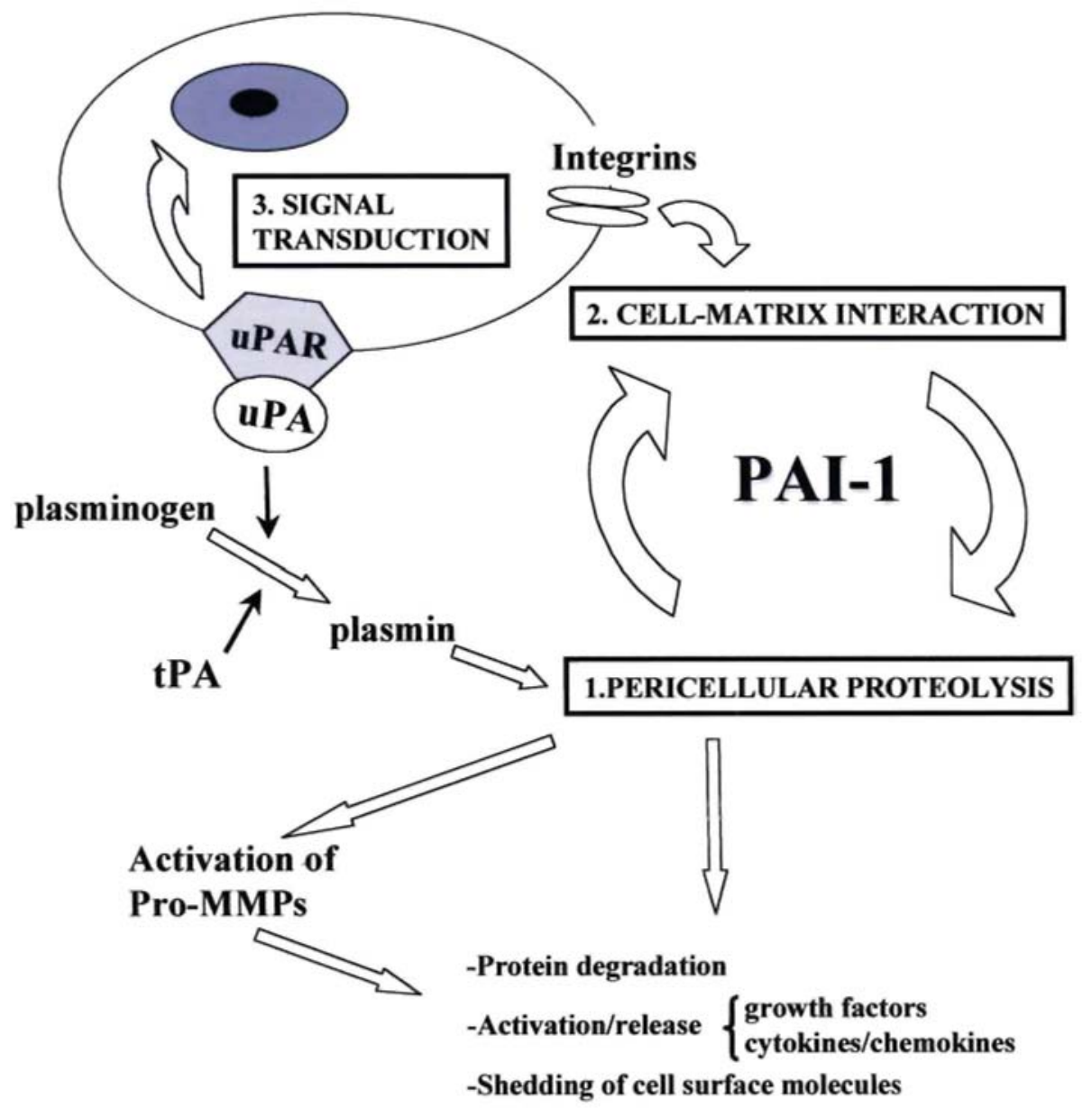

\section{Physiological inhibitors of the plasminogen system}

Different specific, physiological inhibitors of both plasmin (alpha2-antiplasmin) and plasminogen activators (PAI-1 and PAI-2) control the proteolytic activity along the serine proteinase cascade. PAI-1 is believed to be the most abundant fast-acting inhibitor of uPA in vivo. It is secreted in an active, but conformationally unstable form. The lack of disulfide bond to stabilize its ternary structure is likely to confer on the PAI-1 molecule a high degree of conformational plasticity. Free active PAI-1 spontaneously decays into an inactive 'latent' form when in solution in the test tube, or following its secretion in cell culture medium [45]. However, its inhibitory activity is stabilized and prolonged by binding to vitronectin present in plasma, platelets, and ECM [46-48]. The high affinity between vitronectin and PAI-1 raises the possibility that vitronectin may concentrate and localize PAI-1 inhibitory activity to specific tissue areas. Vitronectin is thus considered as a cofactor for PAI-1, regulating both its activity and localization (fig. 2).

PAI-1 binds not only to free uPA, but also to uPAR-bound uPA. The uPA/PAI-1 complex also interacts with the transmembrane $\alpha_{2}$-macroglobulin receptor low-density lipoprotein (LDL) receptor-related protein (LRP), an endocytic receptor. Through the combined action of UPAR and LRP, the UPA/PAI-1 complex is internalized and degraded in lysosomes, whereas the uPAR is recycled back to the cell surface [29,38]. PAI-1 is believed to play a central role in cell adhesion mediated through integrins or the uPAR/uPA complex $([40,46]$. PAI-1 competes with the binding of vitronectin to different integrins such as $\alpha_{\mathrm{v}} \beta_{1}, \alpha_{\mathrm{v}} \beta_{3}, \alpha_{\mathrm{v}} \beta_{5}, \alpha_{11 \mathrm{~b}} \beta_{3}$, and $\alpha_{8} \beta_{1}$ [49]. Accordingly, PAI-1 inhibits integrin-dependent migration of human amnion WISH cells, human carcinoma Hep-2 cells, and smooth muscle cells on vitronectin $[50,51]$. It also promotes cellular migration by decreasing cell adhesion to 
vitronectin [52]. This could explain the release of cells from this matrix protein by an excess of PAI-1. Therefore, the delicate balance between cell adhesion and cell detachment has been proposed to be governed by PAI-1 [53].

Figure 2. PAI-1 and UPAR are multifunctional molecules. UPAR interacts with different cell surface-associated molecules (integrins) and with the extracellular matrix glycoprotein, vitronectin. When PAI-1 is bound to vitronectin, integrin or UPAR-mediated adhesion is inhibited leading to cell detachment.

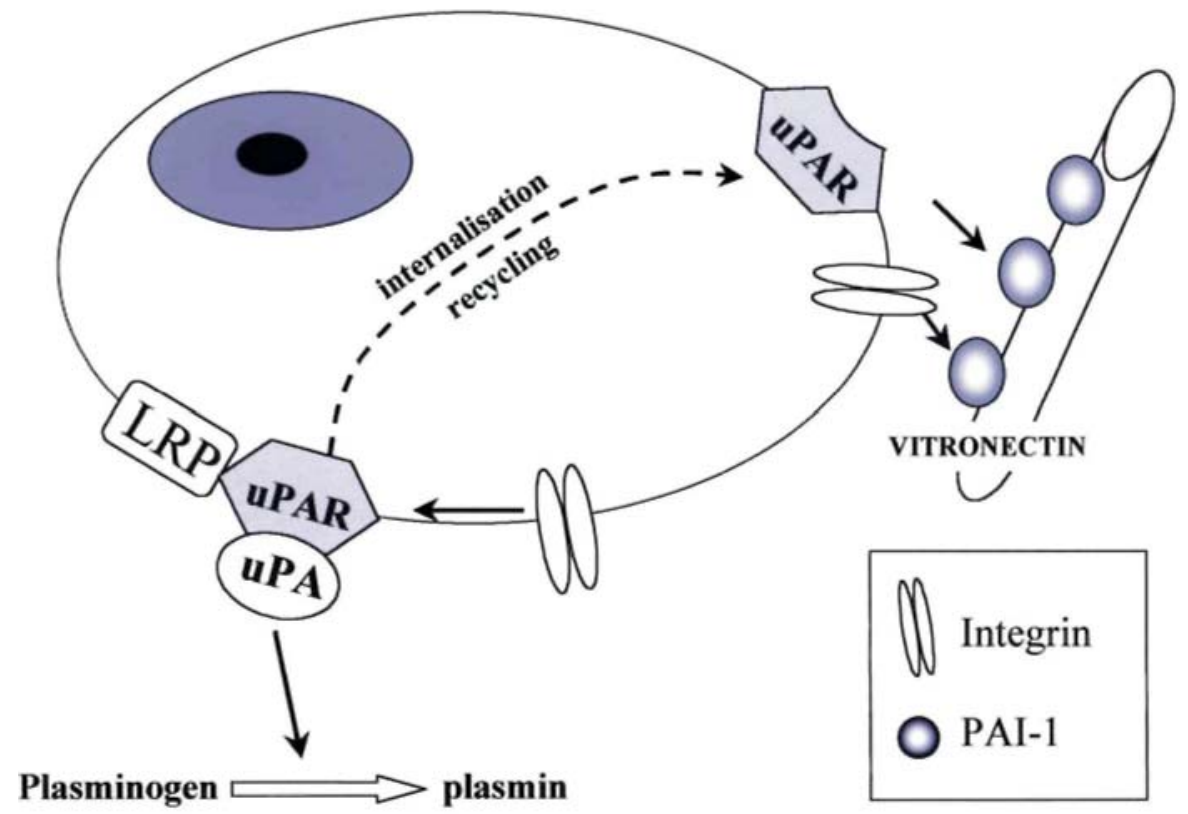

\section{The plasminogen system and angiogenesis}

Quiescent endothelial cells constitutively express t-PA, but net proteolysis is prevented by concomitant expression of PAI-1 [30, 54]. In contrast, when endothelial cells migrate, they upregulate uPA, uPAR and PAI-1 [55-58]. Hypoxia, a major stimulus for angiogenesis has been reported to increase uPAR and PAI-1 expression in endothelial cells [59]. A variety of angiogenic factors (cytokines and growth factors) control the expression of the plasminogen system. VEGF and bFGF synergically induce the expression of uPA, tPA, uPAR, and PAI-1, whereas TGF- $\beta$ downregulates UPA and enhances PAI-1 production [30]. Depending on the situation, PAI-1 is expressed either by endothelial cells themselves or by nonendothelial (stromal and epithelial) cells where it is thought to play a role in the preservation of matrix integrity [30]. In a coculture system of endothelial cells and fibroblasts, PAI-1 mRNA and promoter activity are induced only in a single row of fibroblasts apposed to sprouting but not resting endothelium [60]. Such a paracrine induction may be of importance during sprouting, which constitutes the only period during which endothelial cells establish direct contact with fibroblasts, and may provide a mechanism to counterbalance excessive pericellular proteolysis.

Although inhibition of plasminogen activators reduces endothelial cell migration in vitro, surprisingly, embryonic and postnatal development was unperturbed in mice deficient in uPA and/or tPA, PAI-1, uPAR, plasminogen, or alpha2-antiplasmin [21-27, 30]. Whether this relates to the uselessness of these proteinases in embryonic vessel development or to redundancy or compensation remains to be established. A study on wound healing in plasmino-gen-deficient mice reported that although keratinocyte migration is severely impaired, angiogenesis is not affected in these mice [61]. Although developmental and wound healing-associated angiogenesis appears unaffected in uPA-, uPAR-, tPA-deficient mice, several in vivo studies provide evidence that this proteolytic system is implicated during various pathological angiogenic processes [30]. In the eye, uPA and UPAR are upregulated during development of retinal neovascuarization, which is significantly reduced in uPAR-deficient animals. Regarding tumoral angiogenesis, an increasing number of clinical studies have demonstrated that high UPA, UPAR, and PAI-1 levels indicate a poor prognosis for the survival of patients suffering from a variety of cancers [29, 49, 62, 63]. However, if these high levels are due to tumoral expression, to increased expression by reactive stromal cells recruited to the neoplastic environment, or to both mechanisms 
is unclear. In fact, localization of the protein and mRNA of UPA, uPAR and PAI-1 varies among tumor types. In colon carcinoma, uPA is expressed in cancer cells and PAI-1 is found in endothelial cells [64, 65]. In breast cancer, uPA, uPAR and PAI-1 are expressed in cancer cells and the surrounding stromal cells [66-68]. However, in breast cancer, the expression in fibroblasts rather than in tumor cells seems to have the most impact on the clinical behavior of the disease [69]. The importance of uPA-uPAR interactions during angiogenesis has been documented in a number of in vivo systems [42]. Thus, uPAR antagonists have been developed and tested in various in vivo models (see below). For example, a fusion protein consisting of the receptor-binding aminoterminal fragment of UPA (ATF) and the Fc portion of human IgG inhibit bFGF-induced angiogenesis in subcutaneously injected Matrigel [70]. Similarly, adenovirally delivered ATF specifically inhibits tumor angiogenesis in syngeneic and xenograft murine tumor models [71]. Microvessel density is markedly reduced in tumors developed upon injection of tumor cells transfected with a mutant murine uPA that retains receptor binding but not proteolytic activity [72].

Tumor induced by polyomavirus middle $\mathrm{T}(\mathrm{Pym} \mathrm{T})$ is regarded as a model of endothelial cell tumors and the derived PymT-transformed endothelial cells (End.cells) are suitable to study in vitro the morphogenic behavior of endothelial cells in three-dimensional fibrin gels [73]. The End. cells with increased plasminogen activator activity when compared to nontransformed endothelial cells form cystlike structures when embedded into a fibrin gel. Inhibition of plasmin restores normal morphogenic properties. These findings clearly implicate increased plasminogen activator-plasmin-mediated proteolysis in aberrant vascular morphogenesis [74]. Injection of End. cells into uPA-, tPA-, PAI-1-, or plasminogen-deficient mice demonstrates that tumor growth in vivo is dependent on the generation of uPA-mediated plasmin $[75,76]$. Together, these studies emphasize the importance of balanced proteolysis for angiogenesis and give rise to a model explaining the dual role of proteinases and inhibitors in angiogenesis. Angiogenic endothelial cells require uPA and plasmin to degrade ECM components and migrate. However, plasmin proteolysis needs to be controlled by a physiological inhibitor such as PAI-1 to allow the stabilization of the surrounding ECM and the assembly of endothelial cells into channels.

The plasminogen system, as well as other proteolytic systems [19] may also be implicated in the control of angiogenesis through the generation of proteolytic fragments of the ECM and/or other molecules that display angioregu-latory activities, either positive or negative. Much attention has been focused on angiostatin and endostatin, which are antiangiogenic molecules derived from plasminogen and collagen XVIII, respectively [77, 78]. Recent studies suggest that angiostatin can be generated by limited proteolysis of plasminogen by plasmin, uPA, tPA, or MMPs $[79,80]$. Other negative regulators are fragments of collagen type XV/restin [81] or collagen type IV, such as arresten, from the $\alpha 1$ chain [82], canstatin, from the $\alpha 2$ chain [83], and tumstatin, from the $\alpha 3$ chain [84-86]. Fragments from non-ECM molecules which may have an-gioinhibitory activity include at least MMP-2 (PEX), an-tithrombin [87], calreticulin (vasostatin) [88], and domain 5 of high-molecular-weight kininogen (kininostatin) [89]. However, although a large amount of information has accumulated on the antiangiogenic activity of these fragments, little is know about the proteolytic pathway leading to their release and the relevance of their biological activity in vivo.

\section{Unexpected role of PAI-1 in tumor angiogenesis}

The initially unexpected finding that PAI-1 is a strong negative prognostic marker in cancer could be explained by a simultaneous enhancement in UPA and PAI-1 expression resulting in a net excess of proteolytic activity.

Alternatively, this paradoxical observation may be related to a potential direct role of PAI-1 in cancer cell migration and invasion. Based on its ability to block uPA proteolysis, PAI-1 would be anticipated to impair angiogenesis. However, pulmonary metastases from a sub-population of HT1080 cells were increased by exogenous administration of PAI-1 and reduced by injection of anti-PAI-1 antibody [90]. Studies in PAI-1 deficient mice have revealed an absolute requirement for PAI-1 in tumor angiogenesis. To investigate the role played by the host proteolytic system in tumor invasion and angiogenesis, murine malignant ker-atinocytes plated on a collagen gel were implanted onto the dorsal muscle fascia of uPA-, tPA-, uPA/tPA-, uPARplasminogen-, or PAI-1-deficient mice [91, 92]. The absence of PAI-1 (but not of uPA, uPAR, or tPA) markedly impaired tumor invasion and vascularization. As the tumor cells produced PAI-1, the genotypic effect on tumoral angiogenesis was attributable to PAI-1 produced by host mesenchymal cells and/or sprouting endothelial cells. The importance of plasmin-mediated proteolysis in this model was further supported by the demonstration of delayed angiogenesis observed in plasminogen -/- mice [92]. Since then, the requirement for host PAI-1 during tumor angiogenesis has been confirmed in a fibrosarcoma model in PAI-1 -/-mice [93]. Laser-induced choroidal angiogenesis [94], an ocular model of pathological nontumoral angiogenesis similar to age-related macular degeneration and b-FGF-induced angiogenesis [95] were similarly impaired in PAI-1-deficient mice. 
Furthermore, these in vivo observations are amply supported by results obtained in vitro in the mouse aortic ring model [96]. The essential role of PAI-1 in angiogenesis may be explained by the multifunctional nature of PAI-1 (see above). Although the exact mechanism of PAI-1 action remains to be elucidated at least two models can be proposed. First, by protecting the ECM against excessive degradation, PAI-1 may serve to stabilize the matrix which acts as a scaffold required for endothelial cell migration and the coordinated assembly of endothelial cells into capillaries (fig. 2) [97]. Accordingly, the delayed angiogenesis observed in the absence of plasminogen emphasizes the importance of a tightly controlled plasmin-mediated proteolysis [92]. In addition, the sequestration of PAI-1 in the ECM is consistent with such a role. Thus, a precise balance between proteolytic enzymes and their inhibitors may be essential for endothelial cell migration and differentiation into functional vessels. In the aortic ring assay, no vessels form from PAI-1-deficient animals. Addition of exogenous recombinant PAI-1 at a physiological concentration restores microvessel sprouting, while at 'therapeutical' concentrations, angiogenesis is inhibited [96]. Similarly, PAI-1 inhibits bFGF-induced angiogenesis when added at high concentrations [98]. Thus PAI-1 appears to have a dual function displaying pro-an-giogenic activity at physiological concentrations and anti-angiogenic effects at high, pharmacological concentrations.

A second mechanism of PAI-1 action during angiogenesis could be related to its capacity to interact with uPAR, integrins, and vitronectin, and thereby to control cell migration (see above and fig. 1). When PAI-1 is bound to vitronectin, the integrin adhesion site is cryptic and cellular adhesion is blocked. However, expression of uPA counteracts the PAI-1 anti-adhesive effect by destabilizing the interaction between vitronectin and PAI-1, restoring uPAR-vitronectin interaction, and allowing cellular integral access to the RGD adhesion site. Since cellular migration is considered to result from a succession of attachment and detachment events, this effect of PAI-1 would lead to a migratory phenotype. To address the mechanism of action of PAI-1, adenoviruses were used to deliver two mutant forms of PAI-1 to PAI-1 -deficient mice in the transplantation system mentioned above [92] and in the aortic ring assay [96]. The PAI-1 mutants either (i) bind vitronectin normally but fail to inhibit uPA or tPA or (ii) inhibit PAs normally but have negligible binding to vitronectin. In both in vitro and in vivo models, angiogenesis is restored only by the PAI-1 mutant that retains plasminogen activator inhibitory activity, demonstrating that the PAI-1 requirement is related only to its capacity to inhibit excessive proteolysis rather than to an interaction with vitronectin. Consistent with this, tumor angiogenesis and invasion were observed in vitronectin-deficient mice as well as in wild-type mice [92]. In a separate study using PAI-1 mutants, the inhibition of bFGF-induced angiogenesis in the CAM assay required both the anti-proteinase activity as well as the vitronectin-binding capacity of PAI-1 [98]. Together, these data suggest that depending on the situation, PAI-1 may control angiogenesis by regulating proteolytic and/or nonproteolytic events in endothelial cell migration.

\section{Therapeutic strategies targeting the PA system}

Numerous data collected for various types of solid cancer including at least cancer of the breast, gastrointestinal and urological tracts, lung, brain, ovary, and cervix demonstrate a strong clinical value for the plasminogen system in predicting disease recurrence and survival in cancer patients $[37,99,100]$. In breast cancer, the evaluation of tumor tissue levels of UPA and PAI-1 may help the selection of individualized patient therapy. A prospective randomized multicenter therapy trial validated the prognostic impact of uPA and PAI-1 in nodenegative breast cancer and demonstrated their usefulness as selection criteria for adjuvant chemotherapy [101]. Therefore, both clinical and experimental data render the plasminogen system a promising target for new antitumor therapy concepts. Several approachs have been explored to interfere with the plasminogen system and to reduce tumor growth and metastatic potential [for reviews, see refs $37,42,100$ ]. In the last part of this review, we will briefly summarize the strategies aimed at targeting tumor angiogenesis through the plasminogen/PA system. However, several important issues should be stressed. First, in addition to potential influences on blood coagulation parameters, other side-effects of these treatments and dosing schedules can not be known without clinical application. Second there is no information regarding the stage and type of cancer for which these agents should be administered. In most mice models, these therapies were initiated at early stages of disease and maintained throughout the course of tumor progression. Finally, important lessons could be learned from the disappointing MMP inhibition experience [102].

\section{Inhibition of the synthesis of plasminogen system components}

Studies using anti-sense approaches which lead to decreased uPA or UPAR protein levels have demonstrated anti-tumor effects [103-105]. Transfection of Hep3 carcinoma cells with anti-sense uPAR induces tumor dormancy [106]. 


\section{Inhibition of uPA activity}

The inhibitors of uPA are thought to decrease plasmin activation. Besides their anti-metastatic effects [for reviews, see refs 42,100], some synthetic uPA inhibitors exhibit anti-angiogenic activities. uPA inhibitors such as benzamidine, amiloride, B-428, and B-623 reduce angiogenesis in a chicken embryo chorioallantoic membrane model [107]. An octamer peptide derived from the non-receptor-binding region of uPA reduces tumor angiogenesis in several murine models [108, 109].

\section{Inhibition of uPA-uPAR interactions}

By preventing the binding of uPA to its receptor, uPAR antagonists may interfere both with pericellular proteolysis and cell adhesion and migration. Most approaches have focused on using linear or cyclic peptides based on the sequence of the growth factor domain of uPA $[110,111]$. Despite the promise of such peptides, their usefulness in vivo remains to be established. Peptides are predicted to lack stability due to susceptibility to exoproteinase degradation in the plasma. High-affinity peptide ligands of uPAR that have been identified by phage display $[112,113]$ may circumvent some of the pharmacological problems typically associated with peptide therapy. Alternatively, anti-uPAR antibodies [114] or non-peptidic small-molecule antagonists of uPA binding have been described [100]. In this context, suramin inhibits uPA binding to U937 cells [115]. In addition, it interacts with other molecules involved in angiogenesis such as FGF, insulin-like growth factor, TGF- $\beta$, and others $[116,117]$.

\section{Inhibition of uPA-integrin interactions}

The effects of inhibiting uPAR-integrin interactions have not yet been studied extensively in vivo. However, the peptide M25 identified by phage display [118] has homology to the integrin $\alpha_{M}$ and inhibits the binding of uPA to uPAR [119]. It inhibits leukocyte adhesion to fibrinogen, vitronectin, and endothelial cells.

\section{Delivery of viral vectors to suppress the plasminogen system}

Retroviral- or adenoviral-mediated overexpression of the ATF of uPA in experimental tumors in nude mice reduces primary tumor growth and metastasis by affecting angiogenesis [71]. Adenovirus-mediated delivery of anti-sense targeting uPAR induces the regression of pre-established glioblastoma tumors in vivo [105]. Although adenoviral transfer of PAI-1 reduces metastatic dissemination in mice with intraocular melanoma [120] or HT1080 tumors [121], the dose-dependent effect of PAI-1, pro-angiogenic at low concentration and antiangiogenic at higher ones [92, 96] (Fig. 2), raises questions about the use of PAI-1 or PAI-1 antagonists for inhibition of tumoral angiogenesis.

\section{Inhibition of plasmin activity}

As mentioned above, plasmin generated on the cell surface can be neutralized by aprotinin. A clinical trial reported enhanced 1-year survival with the perfusion of aprotinin during surgery performed on colorectal hepatic metastasis [122]. However, due to the risk of thrombosis, the use of aprotinin is limited to 'strategical' short periods of time characterized by an increased release of tumor cells, as during surgery.

\section{Exploitation of proteolytic activity}

To take advantage of the increased uPA and UPAR expression in malignant human tumors, cytotoxic agents that are activated by uPA or plasmin are being developed. These include proteins containing anthrax toxin fused to sequences cleaved specifically by uPA [123] or an-thracycline non-toxic pro-drugs that can be converted to an active parent drug by uPA [123], plasmin [124], or other serine proteinase such as prostate-specific antigen [125, $126]$.

\section{Conclusions and perspectives}

Increased understanding of the cellular and molecular mechanisms of angiogenesis constitute an essential basis for developing therapeutic strategies to manipulate angiogenesis either positively or negatively [127]. The studies on the PA system reviewed here provide ample evidence for the implication of this proteolytic system during tumoral angiogenesis. While the role of uPA and its receptor has been defined their inhibitor PAI-1 plays an unanticipated role and to date, little is known about the function of TPA in angiogenesis. The data accumulated so far raise the possibility for interfering with the plasminogen activator/plasmin system to 
counteract angiogenesis. The adequacy of interfering with PAI-1 requires further investigations. Therefore, despite recent advances in angiogenesis research, many questions remain unanswered while others are emerging. Another process comparable to angiogenesis, called lymphangiogenesis, is responsible for the formation of new vessels in the lymphatic system and is believed to influence tumor invasion [128]. Although very little is known about the mechanisms of lymphangiogenesis, VEGF-A, VEGF-C, and bFGF are capable of stimulating uPA, uPAR, tPA, and PAI-1 in bovine large-vessel lymphatic endothelial cells [129, 130]. Clearly, both lymphangiogenesis and sprouting angiogenesis participate in tumor vasculature and have become key targets in the war against cancer.

\section{Acknowledgements}

This work was supported by grants from the Communauté Française de Belgique (Actions de Recherches Concertées), the Commission of European Communities, Les Amis des Aveugles (Ghlin), the Fonds de la Recherche Scientifique Médicale, the Fonds National de la Recherche Scientifique, the Fédération Belge Contre le Cancer, the Fortis -Assurances. A. N. is a Research Associate from the National Fund for Scientific Research (FNRS, Brussels, Belgium). M. C., J. M., B. X, M. V., and D. L. are recipients of a grant from FNRS.

\section{References}

1 Carmeliet P. and Jain R. K. (2000) Angiogenesis in cancer and other diseases. Nature 407: 249-257

2 Rafii S. (2000) Circulating endothelial precursors: mystery, reality, and promise. J. Clin. Invest 105: 17-19

3 Yancopoulos G. D., Davis S., Gale N W., Rudge J. S., Wiegand S. J. and Holash J. (2000) Vascular-specific growth factors and blood vessel formation. Nature 407: 242-248

4 Liekens S., De Clercq E. and Neyts J. (2001) Angiogenesis: regulators and clinical applications. Biochem. Pharmacol. 61: 253-270

5 Hanahan D and Folkman J. (1996) Patterns and emerging mechanisms of the angiogenic switch during tumorigenesis. Cell 86: $353-364$

6 Benjamin L. E., Golijanin D., Itin A., Pode D. and Keshet E. (1999) Selective ablation of immature blood vessels in established human tumors follows vascular endothelial growth factor withdrawal. J. Clin. Invest. 103:159-165

7 Richard D. E., Berra E. and Pouyssegur J. (1999) Angiogenesis: how a tumor adapts to hypoxia. Biochem. Biophys. Res. Commun. 266:718-722

8 Folkman J. (1996) Tumor angiogenesis and tissue factor. Nat. Med. 2: 167-168

9 Dvorak H. F., Brown L. F., Detmar M. and Dvorak A. M. (1995) Vascular permeability factor/vascular endothelial growth factor, microvascular hyperpermeability, and angiogenesis. Am. J. Pathol. 146: 1029-1039

10 Eliceiri B. P. and Cheresh D A. (1999) The role of alphav in-tegrins during angiogenesis: insights into potential mechanisms of action and clinical development. J. Clin. Invest. 103: 1227-1230

11 Brooks P. C. (1996) Role of integrins in angiogenesis. Eur. J. Cancer 32A: 2423-2429

12 Scatena M. and Giachelli C. (2002) The alpha(v)beta3 integrin, NF-kappaB, osteoprotegerin endothelial cell survival pathway: potential role in angiogenesis. Trends Cardiovasc. Med 12: 83-88

13 Brooks P. C, Montgomery A. M., Rosenfeld M., Reisfeld R A., Hu T, Klier G et al. (1994) Integrin alpha v beta 3 antagonists promote tumor regression by inducing apoptosis of angiogenic blood vessels. Cell 79: 1157-1164

14 Reynolds L. E., Wyder L., Lively J. C., Taverna D, Robinson D., Huang X. et al. (2002) Enhanced pathological angiogenesis in mice lacking beta3 integrin or beta3 and beta5 integrins. Nat. Med. 8: 27-34

15 Cheresh D. A. and Stupack D. G. (2002) Integrin-mediated death: an explanation of the integrin-knockout phenotype? Nat. Med. 8: 193194

16 Stromblad S., Fotedar A., Brickner H., Theesfeld C, Aguilar D D, Friedlander M. et al. (2002) Loss of p53 compensates for alpha vintegrin function in retinal neovascularization. J. Biol. Chem. 277: 13371-13374

17 Noel A., Gilles C., Bajou K., Devy L., Kebers F, Lewalle J. M. et al. (1997) Emerging roles for proteinases in cancer. Invasion Metastasis 17: 221-239

18 Rifkin D. B., Mazzieri R., Munger J. S., Noguera I. and Sung J. (1999) Proteolytic control of growth factor availability. AP-MIS 107: 
Published in: Cellular \& Molecular Life Sciences (2003), vol. 60, iss.3, pp 463-473

Status: Postprint (Author's version)

$80-85$

19 Egeblad M. and Werb Z. (2002) New functions for the matrix metalloproteinases in cancer progression. Nat. Rev. 2: 163-176

20 Twining S. S. (1994) Regulation of proteolytic activity in tissues. Crit Rev. Biochem. Mol. Biol. 29: 315-383

21 Carmeliet P., Kieckens L., Schoonjans L., Ream B., Nuffelen A. van, Prendergast G. et al. (1993) Plasminogen activator inhibitor-1 gene-deficient mice. I. Generation by homologous recombination and characterization. J. Clin. Invest. 92: 2746-2755

22 Carmeliet P., Stassen J. M., Schoonjans L., Ream B., Oord J. J. van den, De Mol M. et al. (1993) Plasminogen activator inhibitor- 1 gene-deficient mice. II. Effects on hemostasis, thrombosis, and thrombolysis. J. Clin. Invest. 92: 2756-2760

23 Carmeliet P., Schoonjans L., Kieckens L., Ream B., Degen J., Bronson R. et al. (1994) Physiological consequences of loss of plasminogen activator gene function in mice. Nature 368: 419-424

24 Dewerchin M., Nuffelen A. V., Wallays G., Bouche A., Moons L., Carmeliet P. etal. (1996) Generation and characterization of urokinase receptor-deficient mice. J. Clin. Invest. 97: 870-878

25 Lijnen H. R., Okada K., Matsuo O., Collen D. and Dewerchin M. (1999) Alpha2-antiplasmin gene deficiency in mice is associated with enhanced fibrinolytic potential without overt bleeding. Blood 93: 2274-2281

26 Ploplis V A., Carmeliet P., Vazirzadeh S., Van V. I, Moons L. and Plow E. F (1995) Effects of disruption of the plasminogen gene on thrombosis, growth, and health in mice. Circulation 92: 2585-2593

27 Ploplis V A., Wilberding J., McLennan L., Liang Z., Cor-nelissen I., DeFord M. E. et al. (2000) A total fibrinogen deficiency is compatible with the development of pulmonary fibrosis in mice. Am. J. Pathol. 157: 703-708

28 Collen D. and Lijnen H. R. (1991) Basic and clinical aspects of fibrinolysis and thrombolysis. Blood 78: $3114-3124$

29 Andreasen P. A., Kjoller L., Christensen L. and Duffy M. J. (1997) The urokinase-type plasminogen activator system in cancer metastasis: a review. Int. J. Cancer 72: 1-22

30 Carmeliet P. and Collen D. (2000) Transgenic mouse models in angiogenesis and cardiovascular disease. J. Pathol. 190: 387-405

31 Blasi F. (1997) uPA, uPAR, PAI-1: key intersection of proteolytic, adhesive and chemotactic highways? Immunol. Today 18:415-417

32 Lee S. L., Dickson R. B. and Lin C. Y. (2000) Activation of he-patocyte growth factor and urokinase/plasminogen activator by matriptase, an epithelial membrane serine protease. J. Biol. Chem. 275: 36720-36725

33 Schmaier A. H. (2000) Plasma kallikrein/kinin system: a revised hypothesis for its activation and its physiologic contributions. Curr. Opin. Hematol. 7: 261-265

34 Binnema D. J., Dooijewaard G. and Turion P. N. (1991) An analysis of the activators of single-chain urokinase-type plasminogen activator (scu-PA) in the dextran sulphate euglobulin fraction of normal plasma and of plasmas deficient in factor XII and prekallikrein. Thromb. Haemost. 65: 144-148

35 Hall S. W., Humphries J. E. and Gomas S. L. (1991) Inhibition of cell surface receptor-bound plasmin by alpha 2-antiplasmin and alpha 2-macroglobulin. J. Biol. Chem. 266: 12329-12336

36 Plow E. F., Herren T., Redlitz A., Miles L. A. and Hoover-Plow J. L. (1995) The cell biology of the plasminogen system. FASEBJ. 9:939-945

37 Schmitt M., Wilhelm O., Reuning U, Kruger A. and Harbec N. et al. (2000) The urokinase plasminogen activator system as a novel target for tumour therapy. Fibrinolysis Proteolysis 14: 114-132

38 Blasi F. (1999) The urokinase receptor: a cell surface, regulated chemokme. APMIS 107: 96-101

39 Blasi F. (1999) Proteolysis, cell adhesion, chemotaxis, and invasiveness are regulated by the u-PA-u-PAR-PAI-1 system. Thromb Haemost 82: 298-304

40 Chapman H. A. (1997) Plasminogen activators, integrins, and the coordinated regulation of cell adhesion and migration. Curr. Opin. Cell Biol. 9: 714-724

41 Xue W., Mizukami I., Tod R. F. III and Petty H. R. (1997) Urokinase-type plasminogen activator receptors associate with $\beta 1$ and $\beta 33$ integrins of fibrosarcoma cells: dependence on extracellular matrix components. Cancer Res. 57: 1682-1689 
42 Mazar A. P. (2001) The urokinase plasminogen activator receptor (uPAR) as a target for the diagnosis and therapy of cancer. Anticancer Drugs 12: $387-400$

43 Busso N., Masur S. K., Lazega D., Waxman S. and Ossowski L. (1994) Induction of cell migration by pro-urokinase binding to its receptor: possible mechanism for signal transduction in human epithelial cells. J. Cell Biol. 126: 259-270

44 Wei Y., Yang X., Liu Q, Wilkins J. A. and Chapman H. A. (1999) A role for caveolin and the urokinase receptor in inte-grin-mediated adhesion and signaling. J. Cell Biol. 144: 1285-1294

45 Hekman C. M. and Loskutoff D J. (1985) Endothelial cells produce a latent inhibitor of plasminogen activators that can be activated by denaturants. J. Biol. Chem. 260: 11581-11587

46 Loskutoff D. J., Curnden S. A., Hu G. and Deng G. (1999) Regulation of cell adhesion by PAI-1. APMIS 107: 54-61

47 Salonen E. M., Vaheri A., Pollanen J., Stephens R., Andreasen P., Mayer M. et al. (1989) Interaction of plasminogen activator inhibitor (PAI-1) with vitronectin. J. Biol. Chem. 264: 6339-6343

48 Wiman B., Almquist A., Sigurdardottir O. and Lindahl T. (1988) Plasminogen activator inhibitor 1 (PAI) is bound to vitronectin in plasma. FEBS Lett. 242: 125-128

49 SugiuraY., Ma L., Sun B., Shimada H., Laug W. E., Seeger R C. etal. (1999) The plasminogen-plasminogen activator (PA) system in neuroblastoma: role of PA inhibitor-1 in metastasis. Cancer Res. 59: 1327-1336

50 Stefansson S. and Lawrence D. A. (1996) The serpin PAI-1 inhibits cell migration by blocking integrin alpha V beta 3 binding to vitronectin. Nature 383: 441-443

51 Kjoller L., Kanse S. M., KirkegaardT, Rodenburg.W., Ronne E., Goodman S. L. etal. (1997) Plasminogen activator inhibitor- 1 represses integrin- and vitronectin-mediated cell migration independently of its function as an inhibitor of plasminogen activation. Exp. Cell Res. 232: $420-429$

52 Waltz D. A., Natkin L. R., Fujita R. M., Wei Y. and Chapman H. A. (1997) Plasmin and plasminogen activator inhibitor type 1 promote cellular motility by regulating the interaction between the urokinase receptor and vitronectin. J. Clin. Invest. 100: 58-67

53 Deng G, Curriden S. A., Wang S., Rosenberg S. and Loskutoff D. J. (1996) Is plasminogen activator inhibitor-1 the molecular switch that governs urokinase receptor-mediated cell adhesion and release? J. Cell Biol. 134: 1-9

54 Simpson A. J., Booth N. A., Moore N. R. and Bennett B. (1991) Distribution of plasminogen activator inhibitor (PAI-1) in tissues. J. Clin. Pathol. 44: 139-143

55 Bacharach E., Itin A. and Keshet E. (1992) In vivo patterns of expression of urokinase and its inhibitor PAI-1 suggest a concerted role in regulating physiological angiogenesis. Proc. Natl. Acad. Sci. USA 89: 10686-10690

56 Pepper M. S., Vassalli J. D., Montesano R. and Orci L. (1987) Urokinase-type plasminogen activator is induced in migrating capillary endothelial cells. J. Cell Biol. 105: 2535-2541

57 Pepper M. S., Sappino A. P., Montesano R., Orcin L. and Vassalli J. D. (1992) Plasminogen activator inhibitor-1 is induced in migrating endothelial cells. J. Cell Physiol. 153: 129-139

58 Pepper M. S., Sappino A. P., Stocklin R, Montesano R, Orci L. and Vassalli J. D. (1993) Upregulation of urokinase receptor expression on migrating endothelial cells. J. Cell Biol. 122: 673-684

59 UchiyamaT, Kurabayashi M., OhyamaY., Utsugi T., Akuzawa N., Sato M. et al. (2000) Hypoxia induces transcription of the plasminogen activator inhibitor-1 gene through genistein-sen-sitive tyrosine kinase pathways in vascular endothelial cells. Arterioscler. Thromb. Vase. Biol. 20: 1155-1161

60 Bacharach E., Itin A. and Keshet E. (1998) Apposition-dependent induction of plasminogen activator inhibitor type 1 expression: a mechanism for balancing pericellular proteolysis during angiogenesis. Blood 92: 939-945

61 Romer J., Bugge T. H., Pyke C, Lund L. R., Flick M. J., De-gen J. L. et al. (1996) Plasminogen and wound healing. Nat. Med. 2: 725

62 Stephens R. W., Brunner N., Janicke F. and Schmitt M. (1998) The urokinase plasminogen activator system as a target for prognostic studies in breast cancer. Breast Cancer Res. Treat 52:99-111

63 Pedersen H., Brunner N., Francis D., Osterlind K., Ronne E., Hansen H. H. et al.. (1994) Prognostic impact of urokinase, urokinase receptor, and type 1 plasminogen activator inhibitor in squamous and large cell lung cancer tissue. Cancer Res. 54: 4671-4675

64 Naitoh H., Eguchi Y., Ueyama H., Kodama M. and Hattori T. (1995) Localization of urokinase-type plasminogen activator, plasminogen activator inhibitor-1,2 and plasminogen in colon cancer. Jpn. J. Cancer Res. 86: 48-56 
65 Harvey S. R, Sait S. N, Xu Y., Bailey J. L., Pénétrante R. M. and Markus G. (1999) Demonstration of urokinase expression in cancer cells of colon adenocarcinomas by immunohisto-chemistry and in situ hybridization. Am. J. Pathol. 155: 1115-1120

66 Nielsen B. S., Sehested M., Timshel M., Pyke C. and Dano K. (1996) Messenger RNA for urokinase plasminogen activator is expressed in myofibroblasts adjacent to cancer cells in human breast cancer. Lab. Invest. 74: 168-177

67 Umeda T., Eguchi Y., Okino K., Kodama M. and Hattori T. (1997) Cellular localization of urokinase-type plasminogen activator, its inhibitors, and their mRNAs in breast cancer tissues. J. Pathol. 183: 388-397

68 Nielsen B. S., Sehested M., Duun S., Rank F., Timshel S., Ry-gaard J. et al. (2001) Urokinase plasminogen activator is localized in stromal cells in ductal breast cancer. Lab. Invest. 81: 1485-1501

69 Dublin E., Hanby A., Patel N. K., Liebman R. and Barnes D. (2000) Immunohistochemical expression of uPA, uPAR, and PAI-1 in breast carcinoma. Am. J. Pathol. 157: 1219-1227

70 Mm HY., Doyle L. V, Vitt C. R., Zandonella C. L., Stratton-Thomas J. R., Shuman M. A. et al. (1996) Urokinase receptor antagonists inhibit angiogenesis and primary tumor growth in syngeneic mice. Cancer Res. 56: 2428-2433

71 Li H., Lu H., Griscelli F., Opolon P., Sun L. Q., Ragot T. et al. (1998) Adenovirus-mediated delivery of a uPA/uPAR antagonist suppresses angiogenesis-dependent tumor growth and dissemination in mice. Gene Ther. 5: 1105-1113

72 Evans C. P., Elfman F., Parangi S., Conn M., Cunha G. and Shuman M. A. (1997) Inhibition of prostate cancer neovascularization and growth by urokinase-plasminogen activator receptor blockade. Cancer Res. 57: 3594-3599

73 Pepper M. S. (2001) Role of the matrix metalloproteinase and plasminogen activator-plasmin systems in angiogenesis. Arte-rioscler. Thromb. Vasc. Biol. 21: 1104-1117

74 Montesano R, Pepper M. S., Mohle-Steinlein U, Risau W., Wagner E. F. and Orci L. (1990) Increased proteolytic activity is responsible for the aberrant morphogenetic behavior of endothelial cells expressing the middle T oncogene. Cell 62: 435-445

75 Sabapathy K. T., Pepper M. S., Kiefer E, MÖhle-Steinlein U, Tacchini-Cottier F., Fetka I. et al. (1997) Polyoma middle T-in-duced vascular tumor formation: the role of the plasminogen activator/plasmin system. J. Cell Biol. 137: 953-963

76 Lijnen H. R., Wagner E. E and Collen D. (1997) Plasminogen-dependent and -independent proteolytic activity of murine endothelioma cells with targeted inactivation of fibrinolytic genes. Thromb. Haemost. 77: 362-367

77 O'Reilly M. S., Holmgren L., Shing Y., Chen C, Rosenthal R. A., Moses M. et al. (1994) Angiostatin: a novel angiogenesis inhibitor that mediates the suppression of metastases by a Lewis lung carcinoma. Cell 79: 315-328

78 O'Reilly M. S., Boehm T, Shing Y., Fuka N., Vasios G., Lane W. S. et al. (1997) Endostatin: an endogenous inhibitor of angiogenesis and tumor growth. Cell 88: 277-285

79 Stack M. S., Gately S., Bafetti L. M., Enghild J. and Soff G. A. (1999) Angiostatin inhibitits endothelial and melanoma cellular invasion by blocking matrix-enhanced plasminogen activation. Biochem. J. 340: 77-84

80 Gately S., Twardowski P., Stack M. S., Cundiff D. L., Grella D, Castellino F. J. et al. (1997) The mechanism of cancer-mediated conversion of plasminogen to the angiogenesis inhibitor angiostatin. Proc. Natl. Acad. Sci. USA 94: 10868-10872

81 Ramchandran R., Dhanabal M., Volk R, Waterman M. X, Segal M., LU H. etal. (1999) Antiangiogenic activity of restin, NC10 domain of human collagen XV: comparison to endostatin. Biochem. Biophys. Res. Commun. 255: 735-739

82 Colorado P. C., Torre A., Kamphaus G., Maeshima Y., Hopfer H., Takahashi K. et al. (2000) Anti-angiogenic cues from vascular basement membrane collagen. Cancer Res. 60: 2520-2526

83 Kamphaus G. D., Colorado P. C., Panka D. J., Hopfer H., Ramchandran R., Torre A. et al. (2000) Canstatin, a novel matrix-derived inhibitor of angiogenesis and tumor growth. J. Biol. Chem. 275: 1209-1215

84 Maeshima Y., Colorado P. C. and Kalluri R. (2000) Two RGD-independent alpha vbeta 3 integrin binding sites on tumstatin regulate distinct anti-tumor properties. J. Biol. Chem. 275: 23745-23750

85 Maeshima Y., Manfredi M., Reimer C., Holthaus K. A., Hopfer H., Chandamuri B. R. et al. (2001) Identification of the antiangiogenic site within vascular basement membrane-derived tumstatin. J. Biol. Chem 276: 15240-15248

86 Maeshima Y., Yerramalla U. L., Dhanabal M., Holthaus K. A., Barbashov S., Kharbanda S. et al. (2001) Extracellular matrix-derived peptide binds to alpha(v)beta(3) integrin and inhibits angiogenesis. J. Biol. Chem 276: 31959-31968

87 O'Reilly M. S., Pirie-Shepherd S., Lane W. S. and Folkman J. (1999) Antiangiogenic activity of the cleaved conformation of the serpin antithrombin. Science 285: 1926-1928 
88 Pike S. E., Yao L., Xones K. D., Cherney B., Appella E., Saka-guchi K. et al. (1998) Vasostatin, a calreticulin fragment, inhibits angiogenesis and suppresses tumor growth. J. Exp. Med 188: 2349-2356

89 Colman R W., Jameson B. A., Lin Y, Johnson D. and Mousa S. A. (2000) Domain 5 of high molecular weight kininogen (kininostatin) down-regulates endothelial cell proliferation and migration and inhibits angiogenesis. Blood 95: 543-550

90 Tsuojiya H., Katsuo E., Sunayama C., Tomita K., Ueda Y. and Binder B. R. (1995) The antibody to plasminogen activator inhibitor-1 suppresses pulmonary metastases of human fibrosarcoma in athymic mice. Gen. Diagn. Pathol. 141: 41-48

91 Bajou K., Noel A., Gerard R. D, Masson V., Brunner N., Holst-Hansen C. et al. (1998) Absence of host plasminogen activator inhibitor 1 prevents cancer invasion and vascularization. Nat. Med. 4: 923-928

92 Bajou K., Masson V., Gerard R. D., Schmitt P., Albert V, Praus M. et al. (2001) The plasminogen activator inhibitor PAI-1 controls in vivo tumor vascularization by interaction with proteases, not vitronectin: implications for antiangiogenic strategies. J. Cell Biol. 152: 777784

93 Gutierrez L. S., Schulman A., Brito-Robinson T., Noria F., Plo-plis V A. and Castellino F. J. (2000) Tumor development is retarded in mice lacking the gene for urokinase-type plasminogen activator or its inhibitor, plasminogen activator inhibitor-1. Cancer Res. 60: 58395847

94 Lambert V., Munaut C., Noel A., Frankenne F., Bajou K., Gerard R. et al. (2001) Influence of plasminogen activator inhibitor type 1 on choroidal neovascularization. FASEB J.. 15: 1021-1027

95 McMahon G. A., Petitclerc E., Stefansson S., Smith E., Wong M. K., Westrick R. J. et al. (2001) Plasminogen activator inhibitor-1 regulates tumor growth and angiogenesis. J. Biol. Chem. 276: 33964-33968

96 Devy L., Blacher S., Grignet-Debrus C, Bajou K., Masson V, Gerard R. D. et al. (2002) The pro- or antiangiogenic effect of plasminogen activator inhibitor 1 is dose dependent. FASEB J. 16: 147-154

97 Pepper M. S. and Montesano R (1990) Proteolytic balance and capillary morphogenesis. Cell Differ. Dev. 32: 319-327

98 Stefansson S., Petitclerc E., Wong M. K., McMahon G A., Brooks P. C. and Lawrence D. A. (2001) Inhibition of angiogenesis in vivo by plasminogen activator inhibitor-1. J. Biol. Chem. 276: 8135-8141

99 Reuning U., Magdolen V., Wilhelm O., Fischer K., Lutz V., Graeff H. et al. (1998) Multifunctional potential of the plasminogen activation system in tumor invasion and metastasis. Int. J. Oncol. 13: 893-906

100 Muehlenweg B., Sperl S., Magdolen V., Schmitt M. and Har-beck N. (2001) Interference with the urokinase plasminogen activator system: a promising therapy concept for solid tumours. Expert. Opin. Biol. Ther. 1: 683-691

101 Janicke F., Prechtl A., Thomssen C., Harbeck N., Meisner C., Untch M. etal. (2001) Randomized adjuvant chemotherapy trial in highrisk, lymph node-negative breast cancer patients identified by urokinase-type plasminogen activator and plasminogen activator inhibitor type 1. J. Natl. Cancer Inst. 93: 913-920

102 Coussens L. M., Fingleton B. and Matrisian L. M. (2002) Matrix metalloproteinase inhibitors and cancer: trials and tribulations. Science 295: 2387-2392

103 Wilhelm O., Schmitt M., Hohl S., Senekowitsch R. and Graeff H. (1995) Antisense inhibition of urokinase reduces spread of human ovarian cancer in mice. Clin. Exp. Metastasis 13: 296-302

104 Morrissey D., O'Connell J., Lynch D., O'Sullivan G. C., Shanahan F. and Collins J. K. (1999) Invasion by esophageal cancer cells functional contribution of the urokinase plasminogen activation system, and inhibition by antisense oligonucleotides to urokinase or urokinase receptor. Clin. Exp. Metastasis 17: 77-85

105 Mohan E M., Chintala S. K., Mohanam S., Gladson C. L., Kim E. S., Gokaslan Z. L. et al. (1999) Adenovirus-mediated delivery of antisense gene to urokinase-type plasminogen activator receptor suppresses glioma invasion and tumor growth. Cancer Res. 59:3369-3373

106 Aguirre Ghiso J. A., Kovalski K. and Ossowski L. (1999) Tumor dormancy induced by downregulation of urokinase receptor in human carcinoma involves integrin and MAPK signaling. J. Cell Biol. 147: 89-104

107 Swiercz R., Skrzypczak-Jankun E., Merrell M. M., Selman S. H. and Jankun J. (1999) Angiostatic activity of synthetic inhibitors of urokinase type plasminogen activator. Oncol. Rep. 6: 523-526

108 Guo Y., Higazi A. A., Arakelian A., Sachais B. S., Cines D., Goldfarb R. H. et al. (2000) A peptide derived from the nonreceptor binding region of urokinase plasminogen activator (uPA) inhibits tumor progression and angiogenesis and induces tumor cell death in vivo. FASEB J. 14: 1400-1410 
109 Mishima K., Mazar A. P., Gown A., Skelly M., Ji X. D., Wang X. D. et al. (2000) A peptide derived from the non-receptor-binding region of urokinase plasminogen activator inhibits glioblastoma growth and angiogenesis in vivo in combination with cisplatin. Proc. Natl. Acad. Sci. USA 97: 8484-8489

110 Kobayashi H., Gotoh J., Fujie M., Shinohara H., Moniwa N. and Terao T. (1994) Inhibition of metastasis of Lewis lung carcinoma by a synthetic peptide within growth factor-like domain of urokinase in the experimental and spontaneous metastasis model. Int. J. Cancer 57: $727-733$

111 Burgle M., Koppitz M., Riemer C., Kessler H., Konig B., Weidle U. H. et al. (1997) Inhibition of the interaction of urokinase-type plasminogen activator (uPA) with its receptor (UPAR) by synthetic peptides. Biol. Chem 378: 231-237

112 Goodson R. J., Doyle M. V., Kaufman S. E. and Rosenberg S. (1994) High-affinity urokinase receptor antagonists identified with bacteriophage peptide display. Proc. Natl. Acad. Sci. USA 91:7129-7133

113 Fong S., Doyle M. V, Goodson R. J., Drummond R. J., Strat-ton J. R., McGuire L. et al. (2002) Random peptide bacteriophage display as a probe for urokinase receptor ligands. Biol. Chem. 383: 149-158

114 Luther T., Magdolen V., Albrecht S., Kasper M., Riemer C., Kessler H. et al. (1997) Epitope-mapped monoclonal antibodies as tools for functional and morphological analyses of the human urokinase receptor in tumor tissue. Am. J. Pathol. 150: 1231-1244

115 Behrendt N., Ronne E. and Dano K. (1993) Binding of the urokinase-type plasminogen activator to its cell surface receptor is inhibited by low doses of suramin. J. Biol. Chem 268: 5985-5989

116 Botta M., Manetti F. and Corelli F. (2000) Fibroblast growth factors and their inhibitors. Curr. Pharm. Des. 6: 1897-1924

117 Zugmaier G., Favoni R., Jaeger R., Rosen N. and Knabbe C. (1999) Polysulfated heparinoids selectively inactivate heparin-binding angiogenesis factors. Ann. N. Y. Acad. Sci. 886: 243-248

118 Wei Y., Lukashev M., Simon D. I., Bodary S. C, Rosenberg S., Doyle M. V. et al. (1996) Regulation of integrin function by the urokinase receptor. Science 273: 1551-1555

119 Simon D. I., Wei Y., Zhang L., Rao N. K., Xu H, Chen Z. et al. (2000) Identification of a urokinase receptor-integrin interaction site: promiscuous regulator of integrin function. J. Biol. Chem. 275: 10228-10234

120 Ma D., Gerard R. D., Li X. Y., Alizadeh H. and Niederkorn J. Y. (1997) Inhibition of metastasis of intraocular melanomas by adenovirus-mediated gene transfer of plasminogen activator inhibitor type 1 (PAI-1) in an athymic mouse model. Blood 90: $2738-2746$

121 Praus M., Wauterickx K., Collen D. and Gerard R. D. (1999) Reduction of tumor cell migration and metastasis by adenoviral gene transfer of plasminogen activator inhibitors. Gene Ther. 6: 236

122 Lentschener C., Li H., Franco D., Mercier F. J., Lu H., Soria J. et al. (1999) Intraoperatively administered aprotinin increases one year survival after elective liver resection for colorectal metastasis. Proteolysis Fibrinolysis 13: 39-45

123 Liu S., Bugge T. H. and Leppla S. H. (2001) Targeting of tumor cells by cell surface urokinase plasminogen activator-dependent anthrax toxin. J. Biol. Chem. 276: 17976-17984

124 Chakravarty P. K., Carl P. L., Weber M. J. and Katzenellen-bogen J. A. (1983) Plasmin-activated prodrugs for cancer chemotherapy. 2. Synthesis and biological activity of peptidyl derivatives of doxorubicin. J.Med. Chem. 26: 638-644

125 Khan S. R. and Denmeade S. R. (2000) In vivo activity of a PSA-activated doxorubicin prodrug against PSA-producing human prostate cancer xenografts. Prostate 45: 80-83

126 DiPaola R. S., Rinehart J., Nemunaitis J., Ebbinghaus S., Rubin E., Capanna T. et al. (2002) Characterization of a novel prostatespecific antigen-activated peptide- doxorubicin conjugate in patients with prostate cancer. J. Clin. Oncol. 20: 1874-1879

127 Griffioen A. W. and Molema G. (2000) Angiogenesis: potentials for pharmacologic intervention in the treatment of cancer, cardiovascular diseases, and chronic inflammation. Pharmacol. Rev. 52: 237-268

128. Van Trappen P. O. and Pepper M. S. (2002) Lymphatic dissemination of tumour cells and the formation of micrometas-tases. Lancet Oncol. 3: 44-52

129 Pepper M. S., Mandriota S. J., Jeltsch M., Kumar V. and Alitalo K. (1998) Vascular endothelial growth factor (VEGF)-C syn-ergizes with basic fibroblast growth factor and VEGF in the induction of angiogenesis in vitro and alters endothelial cell extracellular proteolytic activity. J. Cell Physiol. 177: 439-452

130 Leak L. V., Saunders M., Day A. A. and Jones M. (2000) Stimulation of plasminogen activator and inhibitor in the lymphatic endothelium. Microvasc. Res. 60: 201-211 